$16^{\circ}$ USIHC - Congresso Internacional de Ergonomia e Usabilidade de

\title{
A ANÁLISE DA INTERFACE DE UM BLOG : PROPOSTA DE MELHORIA DA EXPERIÊNCIA DO USUÁRIO A PARTIR DE DADOS DE USO OBTIDOS EM WEB
}

\section{ANALYSIS OF A BLOG INTERFACE: PROPOSAL TO IMPROVE THE USER EXPERIENCE BASED ON USAGE DATA OBTAINED FROM WEB ANALYTICS}

\author{
Bruna Rovere Reginato ${ }^{1}$, Esp. \\ Julio Monteiro Teixeira², D.Sc. \\ Berenice Gonçalves ${ }^{3}$, D.Sc. \\ Alice Cybis Pereira ${ }^{4}, \mathrm{PhD}$
}

(1) UFSC

e-mail: brunareginato@gmail.com

(2) UFSC

e-mail:juliomontex@gmail.com

(3) UFSC

e-mail: bereni.gon@gmail.com

(4) UFSC

e-mail: acybis@gmail.com

Experiência do Usuário; Web analytics; Google Analytics; Hotjar; Blog

\begin{abstract}
As formas de fazer, consumir, divulgar e mensurar o impacto da informação evoluíram significativamente nas últimas décadas. O mercado disponibiliza diferentes ferramentas de web analytics, contudo, nem sempre os analistas, designers e desenvolvedores conseguem transformar os dados capturados por tais ferramentas em melhorias significativas para a experiência do usuário. Portanto, essa pesquisa visa demonstrar como dados de web analytics podem ser utilizados para melhorar a interface de um blog. Para tanto, um site-caso foi analisado a partir de duas ferramentas, são elas: Google Analytics e Hotjar. Após a análise dos dados, as principais constatações relacionadas a experiência do usuário foram transformadas um plano de melhorias que reúne as principais ações sugeridas.
\end{abstract}

\section{User Experience; Web analytics; Google Analytics; Hotjar; Blog}

The ways of making, consuming, disseminating, and measuring the impact of information have evolved significantly in recent decades. The market provides different web analytics tools, however, analysts, designers and developers are not always able to transform the data captured by such tools into meaningful improvements to the user experience. Therefore, this research aims to demonstrate how web analytics data can be used to improve the interface of a blog. For that, a site-case was analyzed from two tools, they are: Google Analytics and Hotjar. After analyzing the data, the main findings related to the user experience were transformed into an improvement plan that brings together the main suggested actions. 


\section{$16^{\circ}$ \\ ERGODESIGN USIHC CINAHPA}

$16^{\circ}$ Ergodesign - Congresso Internacional de Ergonomia e Usabilidade de Interfaces Humano Tecnológica: Produto, Informações Ambientes Construídos e Transporte

$16^{\circ}$ USIHC - Congresso Internacional de Ergonomia e Usabilidade de Interfaces Humano Computador

CINAHPA | 2017 - Congresso Internacional de Ambientes Hipermídia para Aprendizagem.

\section{Introdução}

As tecnologias da informação e comunicação (TICs) e suas configurações robustas de redes computacionais permitiram um novo fluxo informacional que promove mudanças estruturais na forma como são produzidas, distribuídas e consumidas. Terra (2012, p. 19) afirma: "As novas tecnologias da comunicação alteraram completamente a maneira de se fazer e consumir informação."

Como uma peça importante para este novo cenário surgem os blogs, páginas na web que, por sua facilidade de criação e manutenção, possibilitam que o usuário que desconhece linguagens técnicas de criação de sites produza e publique seu próprio conteúdo. Segundo o site oficial do Wordpress ${ }^{1}$, um dos sistemas de gerenciamento de conteúdo para blogs mais utilizado no mundo, aproximadamente 409 milhões de pessoas visitam mais de 23 bilhões de páginas de blogs a cada mês, enquanto os usuários produzem cerca de 65 milhões de novos posts também a cada mês.

Com isso, pode-se levantar o atual cenário que valoriza do design centrado no usuário para o desenvolvimento das interfaces digitais também no desenvolvimento de blogs, e a importância de conhecer suas características, hábitos, preferências e necessidades como fator determinante para criar uma experiência do usuário agradável. Para acompanhar como acontece a experiência ao operar uma interface existem métodos de avaliação que envolvem desde observação até uso de ferramentas de verificação e entendimento das ações e comportamentos do usuário ao lidar com uma interface. Portanto, a pesquisa teve como objetivo central, demonstrar como dados de web analytics podem ser utilizados para melhorar a interface de um blog.

\section{Fundamentação teórica}

\section{$2.1 \mathrm{Blogs}$}

1 https://wordpress.com/activity/ - acesso em 15/11/2016.
Orduña (2006) afirma que os blogs são páginas pessoais que, como um diário online, tem a possibilidade de publicar na rede ao alcance de todos os usuários, e tem multiplicado as opções dos internautas de publicar na rede conteúdos próprios, sem intermediários, atualizados e de grande visibilidade para os buscadores. $\mathrm{O}$ autor afirma ainda que a apropriação da internet por novos autores que produzem conteúdo caracteriza que a agenda pública não está mais exclusivamente marcada pelos grandes meios, e que velhos e novos autores compartilham protagonismo em um sistema comunicativo renovado.

Entretanto, esse ambiente não foi tão favorável desde o surgimento da rede de computadores. No início dos anos 90, existia a dificuldade de publicação de conteúdos por usuários sem conhecimentos técnicos, pois as páginas precisavam ser codificadas em linguagem $\mathrm{HTML}^{2}$, criadas e publicadas com softwares que demandavam conhecimentos específicos e avançados. Dessa forma pode-se afirmar que os blogs contribuíram para uma mudança neste cenário, pois junto com sua criação surgiram ferramentas de gerenciamento de conteúdo para web, também conhecidas como CMS - Content Management System, que possibilitaram a criação e publicação de sites por usuários leigos em programação, de forma rápida e simples. Orduña (2006, p.16) afirma "Os serviços de edição e publicação de blogs resolvem de um modo fácil e intuitivo esses obstáculos técnicos, e permitem ao usuário concentrar-se na tarefa de elaborar conteúdos, tornando-a tão fácil e intuitiva como o uso do e-mail."

\subsection{Experiência do usuário}

No desenvolvimento de produtos digitais o cenário em que os usuários conseguem, através da interface, atingir seus objetivos e sentir-se satisfeitos e felizes pode ser fator determinante para o sucesso de um produto. Neste contexto, surge o conceito de experiência do usuário, que é hoje amplamente utilizado porém não possui

\footnotetext{
2 Sigla utilizada para se referir a linguagem de marcação de hipertexto (Hipertext Markup Language).
}

Realização:

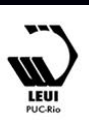




\section{$16^{\circ}$ \\ ERGODESIGN USIHC CINAHPA}

$16^{\circ}$ Ergodesign - Congresso Internacional de Ergonomia e Usabilidade de Interfaces Humano Tecnológica: Produto, Informações Ambientes Construídos e Transporte

$16^{\circ}$ USIHC - Congresso Internacional de Ergonomia e Usabilidade de Interfaces Humano Computador

CINAHPA | 2017 - Congresso Internacional de Ambientes Hipermídia para Aprendizagem. definição única.

Segundo Roto et al. (2011), por ser multidisciplinar, o conceito de $\mathrm{UX}^{3}$ tem lidado com diversas definições e perspectivas, onde cada um aborda o conceito com um ponto de vista diferente. Para Hassenzahl \& Tractinsky (2006) a experiência do usuário pode ser definida a partir de três tópicos, sendo (1) a consequência do estado interno de um usuário, como suas expectativas, necessidades, motivações, estado de humor, etc., (2) as características do sistema projetado, como a sua complexidade, finalidade, usabilidade ou funcionalidade e (3) as características do contexto ou ambiente dentro qual a interação ocorre, por exemplo a configuração organizacional ou social, a significação da atividade, o quão voluntária é a utilização, etc. Em um conceito mais simples, Hassenzahl (2008) descreve UX como um sentimento de avaliação primária e momentânea (boa ou ruim) durante a interação com um produto ou serviço.

Suas raízes podem ser encontradas nos princípios do design centrado no ser humano (HCD - Human Centred Design). Porém, os fatores que afetam o UX são mais amplos e diversificados do que aqueles tradicionalmente tratados no âmbito de HCD. Enquanto fatores tradicionais de usabilidade são geralmente relacionados com o desempenho e interação fluida, os novos fatores de UX se relacionam com afeto, interpretação e significado.

\subsection{Web Analytics}

Segundo Arikan (2008, apud Rogers, Preece e Sharp, 2013) web analytics é a medição, coleta, análise e geração de relatórios de dados da internet, a fim de compreender e otimizar o uso da web. Esses dados acompanham o comportamento dos usuários em uma página da web, como: quanto tempo permanecem na página, onde clicam, a partir de que sites vieram, quais caminhos percorreram e assim por diante. A partir de registro de dados de navegação e interação dos usuários pode-se avaliar se os objetivos dos usuários estão sendo atendidos.

\footnotetext{
${ }^{3}$ Sigla utilizada para se referir a User ("U”) Experience ("X").
}

Beasley (2013) afirma que web analytics revela como grandes grupos de usuários se movem em um site, ampliando os aspectos quantificáveis dos métodos de UX, saindo do universo de pequenas amostras para todo o universo de visitantes de um site.

Uma das principais ferramentas para acompanhar dados de uso de interface é o Google Analytics. O Analytics oferece relatórios baseados em métricas e dimensões, onde definimos o período do relatório e a amostra desejada, que pode ser o número de usuários, número de visitas ou de visualizações de página (pageviews).

\section{Procedimentos metodológicos}

O objeto-caso a ser analisado é o blog do professor Julio Monteiro Teixeira, caracterizado como "Julio Montex". O blog, que existe desde 2012, se propõem a divulgar textos relativos a área de design gráfico, em temas como branding, ergonomia e usabilidade, gestão de design, gestão de projetos, entre outros. As etapas metodológicas envolvem (1) apresentação do blog, (2) apresentação das ferramentas utilizadas, (3) coleta e análise de dados, (4) resultados a partir das constatações e ações sugeridas.

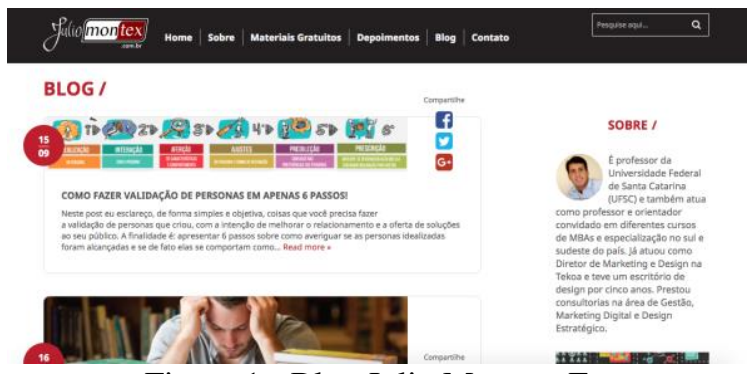

Figura 1 - Blog Julio Montex. Fonte: juliomontex.com.br - acesso em 15/11/2016.

\subsection{Ferramentas adotadas na análise}

\subsubsection{Google Analytics}

O período analisado compreende um período total de 3 meses, entre novembro de 2016 a janeiro de 2017. Foram registrados pela ferramenta do Google Analytics um total de 2.770 visitas, sendo
Realização:

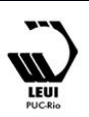




\section{$16^{\circ}$ \\ ERGODESIGN USIHC CINAHPA}

$16^{\circ}$ Ergodesign - Congresso Internacional de Ergonomia e Usabilidade de Interfaces Humano Tecnológica: Produto, Informações Ambientes Construídos e Transporte

$16^{\circ}$ USIHC - Congresso Internacional de Ergonomia e Usabilidade de Interfaces Humano Computador

CINAHPA | 2017 - Congresso Internacional de Ambientes Hipermídia para Aprendizagem.

\subsection{5 usuários únicos.}

\subsubsection{Hotjar}

A partir dos dados obtidos com o Google Analytics, buscou-se para um entendimento mais aprofundado a partir de mapas de calor ${ }^{4}$ e gravação de interações fornecidos pela ferramenta Hotjar. O período analisado foi semelhante ao anterior, de novembro de 2016 a janeiro de 2017, com algumas particularidades da versão gratuita da ferramenta, utilizada neste trabalho. Os mapas de calor foram registrados nas três páginas mais visitadas do site: home, página de materiais e publicação de blog sobre concurso para professor.

\section{Análise de dados}

Observou-se que os usuários navegam aproximadamente em 2,27 páginas a cada sessão. A duração média da sessão/visita ficou em 2:45, com uma taxa de rejeição ${ }^{5}$ de $62,24 \%$. O número de usuários que visitaram o site a partir de computadores/notebooks é expressiva, um total de $80 \%$, contra apenas $18 \%$ em celulares e $2 \%$ em tablets. Outra diferença observada é a média de páginas visualizadas, taxa de rejeição e duração da visita, que representam um menor interesse $\mathrm{e}$ permanência no site para visitas a partir de dispositivos móveis.

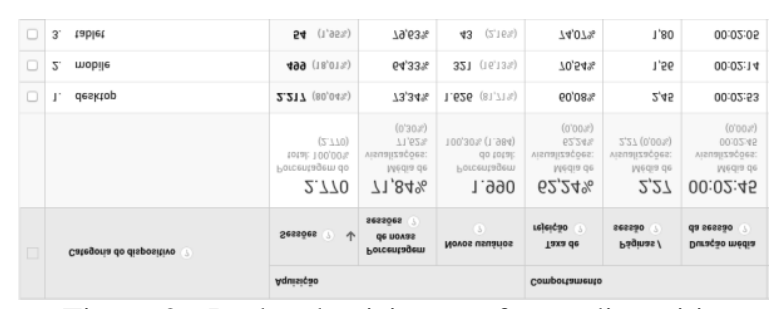

Figura 2 - Dados de visitas conforme dispositivos. Fonte: Google Analytics.

\footnotetext{
4 Mapa de calor é uma representação através de cores das áreas onde aconteceram interações em uma interface, sendo que as cores quentes representam altos índices de interação e as cores frias pequenas quantidades. A interação mapeada pode ser a rolagem da tela, movimento do mouse ou cliques.

5 Taxa de rejeição é a porcentagem de visitantes do site que finalizou a visita sem realizar nenhuma interação nos links disponíveis.
}

Quanto a origem dos visitantes, destaca-se que a maior parte do tráfego do site, cerca de $74 \%$, é a partir de busca orgânica, ou seja, mecanismos de pesquisa na web (excluindo os anúncios). As demais visitas dividem-se entre tráfego direto (quando o usuário digita o endereço do site no navegador), links de outros sites, links de e-mail e links em redes sociais, nessa ordem.

Outra questão a ser analisada são as páginas de destino, ou páginas de entrada no site em que as visitas são iniciadas. O ponto de destaque é que mais de $50 \%$ das visitas do site são iniciadas a partir de um mesmo artigo do blog, que fornece dicas para professores que participam de concursos públicos. Para buscar um entendimento mais aprofundado dessa informação, pode-se realizar o cruzamento entre página de destino e origem da visita, que apontou como origem orgânica quase todas as visitas e esse artigo. Pode-se considerar esse fato como um indicativo de que o autor obteve um bom posicionamento nos mecanismos de busca. A segunda página de destino mais recorrente é a home do site, com aproximadamente $12 \%$ das ocorrências, e origem dividida entre busca orgânica e tráfego direto.

Ao analisar o comportamento dos usuários durante a navegação no site, buscou-se verificar o uso dos recursos oferecidos pelo site. A ferramenta de busca foi utilizada em apenas 12 momentos, sendo buscadas palavras assuntos como branding, ergonomia, gestão do design e personas. A página de materiais gratuitos para download foi visitada 265 vezes, sendo que em 41 das visitas $(15,5 \%)$ houve navegação até a segunda página que lista os materiais em $22(8,3 \%)$ até a terceira página. A opção de filtro por perfil foi utilizada 98 vezes, sendo que em 39 ocorrências $(39,8 \%)$ foi selecionado o perfil do tipo "profissional", em 32 (32,6\%) o perfil do tipo "aluno" e em $27(27,5 \%)$ o perfil do tipo "professor".

A partir dos dados fornecidos pela ferramenta Hotjar, alguns pontos podem ser destacados. No texto sobre concurso para professor universitário notou-se que $50 \%$ dos visitantes rolaram a página até o final do artigo, enquanto nas demais páginas a média foi de $12 \%$. Na página de materiais, os 


\section{$16^{\circ}$ \\ ERGODESIGN USIHC CINAHPA}

$16^{\circ}$ Ergodesign - Congresso Internacional de Ergonomia e Usabilidade de Interfaces Humano Tecnológica: Produto, Informações Ambientes Construídos e Transporte

$16^{\circ}$ USIHC - Congresso Internacional de Ergonomia e Usabilidade de Interfaces Humano Computador

CINAHPA | 2017 - Congresso Internacional de Ambientes Hipermídia para Aprendizagem. principais pontos de clique registrados foram a navegação por categoria e a paginação, seguido pela definição de perfil. Já na home, os locais mais clicados foram as setas do slideshow e o menu.

\section{Resultados}

Como o estudo teve caráter analítico, optou-se por apresentar um quadro propositivo com ações de melhorias sugeridas ao site, a partir de uma síntese das principais constatações identificadas no tópico 4. Análise de dados.

\begin{tabular}{|c|c|}
\hline \multicolumn{2}{|c|}{ Sobre a navegação: } \\
\hline Constatação: & Ação sugerida: \\
\hline $\begin{array}{l}\text { A página de materiais } \\
\text { gratuitos foi acionada ( } 265 \\
\text { vezes). No entanto, apenas } \\
\text { em } 41 \text { visitas }(15,5 \%) \text { houve } \\
\text { navegação até a segunda } \\
\text { página e somente em } 22 \\
\text { visitas }(8,3 \%) \text { o usuário } \\
\text { visualizou a terceira página. } \\
\text { Pode-se concluir que, há } \\
\text { interesse do usuário em } \\
\text { conhecer os materiais } \\
\text { gratuitos disponíveis. } \\
\text { Porém, como existem } \\
\text { muitos materiais a maioria } \\
\text { ( } 84,5 \%) \text { ou encontra o } \\
\text { conteúdo ou desiste na } \\
\text { primeira página. }\end{array}$ & $\begin{array}{l}\text { Portanto,uma melhoria seria mudar a } \\
\text { forma de exposição do conteúdo, ao } \\
\text { invés páginas, poderia apresentar } \\
\text { todos os materiais no modo on page e } \\
\text { carregar conforme abaixa-se a barra } \\
\text { de rolagem (como o feed de notícias } \\
\text { do facebook). } \\
\text { Pode-se também buscar um novo } \\
\text { layout para disponibilizar o filtro por } \\
\text { perfil e categoria, que ocupe menos } \\
\text { espaço na primeira tela de corte do } \\
\text { site. Além disso, os materiais podem } \\
\text { ser exibidos a partir de um grid de } 4 \\
\text { colunas, que exibiria mais opções de } \\
\text { conteúdos a cada rolagem de tela. }\end{array}$ \\
\hline $\begin{array}{l}\text { O filtro por tema mostrou-se } \\
\text { uma ferramenta relevante, } \\
\text { pois foi utilizado } 98 \text { vezes. } \\
\text { Cabe ressaltar que esse filtro } \\
\text { já havia sido sugerido como } \\
\text { trabalho futuro em uma } \\
\text { análise feita por Teixeira, } \\
\text { Benedet e Pinto (2016). A } \\
\text { análise dos autores foi } \\
\text { realizada em uma versão } \\
\text { anterior do mesmo site. }\end{array}$ & $\begin{array}{l}\text { Aprimorar para deixar a ferramenta } \\
\text { ainda mais assertiva facilitando a } \\
\text { busca por materiais e a navegação. } \\
\text { Permitir a combinação entre filtros, } \\
\text { por perfil e tema. } \\
\text { Após essas constatações algumas } \\
\text { modificações já estão sendo feitas: 1) } \\
\text { anteriormente o sistema } \\
\text { administrativo do site só permitia } \\
\text { marcar uma categoria no material, } \\
\text { agora isso já é possível; e 2) para } \\
\text { facilitar a navegação em por } \\
\text { conteúdos em inglês, foi adicionado } \\
\text { uma opção no momento do cadastro } \\
\text { que possibilita identificar e priorizar } \\
\text { conteúdos disponíveis na língua } \\
\text { inglesa durante a navegação. }\end{array}$ \\
\hline $\begin{array}{l}\text { Em } 2770 \text { sessões, a } \\
\text { ferramenta de busca foi } \\
\text { utilizada em apenas } 12 \\
\text { momentos }(0,43 \% \text { das } \\
\text { sessões }) \text {, sendo buscadas } \\
\text { palavras assuntos como }\end{array}$ & $\begin{array}{l}\text { Modificar o local e a configuração } \\
\text { visual da ferramenta de busca do site. } \\
\text { Fixar a barra de menu ao rolar a tela, } \\
\text { para deixar a ferramenta de pesquisa } \\
\text { sempre disponível na tentativa de } \\
\text { aumentar o número de buscas }\end{array}$ \\
\hline
\end{tabular}

branding, ergonomia, gestão do design e personas.

realizadas no site e por consequência o número de páginas visitadas e o tempo de navegação no site.

Sobre o conteúdo:

\begin{tabular}{|l|l|}
\hline Constatação: & Ação sugerida: \\
\hline $\begin{array}{l}\text { As páginas concurso para } \\
\text { professor (1) e home (2) são } \\
\text { as páginas de destino mais } \\
\text { acessadas. O item (1) ainda } \\
\text { era um conteúdo recente e } \\
\text { pouco acessado na análise } \\
\text { feita por Teixeira, Benedet e }\end{array}$ & $\begin{array}{l}\text { O SEO }{ }^{6} \text { de (1), bem como a estratégia } \\
\text { entendido como boa prática para a } \\
\text { criação dos próximos conteúdos. } \\
\text { Quanto ao item (2) deve-se trabalhar } \\
\text { para melhorar o SEO da home. }\end{array}$ \\
\hline $\begin{array}{l}\text { Pinto (2016). } \\
\text { professor universitário } \\
\text { notou-se que 50\% dos } \\
\text { visitantes rolaram a página } \\
\text { até o final do artigo, } \\
\text { enquanto nas demais } \\
\text { páginas a média foi de 12\%. }\end{array}$ & $\begin{array}{l}\text { A forma de apresentação do conteúdo } \\
\text { e a linguagem do texto neste post } \\
\text { também deve ser visto como uma boa } \\
\text { prática. A rolagem até o final em 50\% } \\
\text { dos casos indica que: a escolha das } \\
\text { tags (H1, H2 e H3); a linguagem } \\
\text { utilizada; e o conteúdo foram } \\
\text { adequados. Pois, esses usuários a } \\
\text { rolarem toda a barra para ver todo o } \\
\text { conteúdo. }\end{array}$ \\
\hline
\end{tabular}

Quadro 2: Principais constatações e ações sugeridas.

\section{Considerações finais}

Primeiramente cabe salientar que a pesquisa apresenta exemplos aplicados de como gerar insights para melhorias em sites a partir de dados quantitativos sobre o comportamento dos usuários.

Com relação à ferramenta Google Analytics, percebeu-se que desde a publicação de Fang (2007) e Waisberg e Kaushik (2009) novas funcionalidades foram lançadas e os recursos já existentes naquela época também foram aprimorados e ampliados. No entanto, as métricas mais básicas como: visitas, bounce rate, page views, média de tempo na página e porcentagem de novos visitantes ainda são indicadores importantes do comportamento do consumidor. Atualmente pode-se analisar esses indicadores de

6 SEO é a sigla para "Search Engine Optimization", que significa "otimização para mecanismos de busca", ou otimização de sites. SEO é o conjunto de estratégias com o objetivo de potencializar e melhorar o posicionamento de um site nas páginas de resultados naturais (orgânicos) nos sites de busca.
Realização:

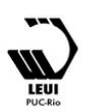




\section{$16^{\circ}$ \\ ERGODESIGN USIHC CINAHPA}

forma combinada com outros recursos do próprio Google Analytics ou de ferramentas complementares como o Hotjar.

Cabe complementar que Fang (2007) ressaltou em sua publicação que apesar de a ferramenta Google Analytics oferecer uma interface fácil e amigável para relatar fatos sobre o site monitorado, ela não consegue fazer sugestões sobre como aprimorá-lo ${ }^{7}$. Hoje em dia diversas ferramentas e recursos conseguem fazer tais sugestões. No entanto, acredita-se que a capacidade do analista quando munido de dados obtidos, por meio dessas ferramentas de tracking como o Google Analytics e o Hotjar, com conhecimento dos recursos e limitações do site, do conteúdo ofertado e do perfil dos usuários pode chegar a soluções mais humanizadas e inovadoras.

Como sugestão para trabalhos futuros, propõem-se a implementação de funis de conversão e metas para acompanhar o caminho realizado pelo usuário até atingir o objetivo definido como estratégico pelos autores do site. As metas podem ser definidas em ações como preenchimentos de formulários de contato, taxa de rolagem de tela e cliques em locais estratégicos, como os botões de download de materiais. Também sugere-se uma análise comparativa entre as versões de em português e inglês do site, já que até o momento de conclusão deste artigo a última não obteve número expressivo de visitas que justificasse a pesquisa.

\section{Referências Bibliográficas}

BEASLEY, Michael. Practical Web Analytics for User Experience: How Analytics Can Help You Understand Your Users. Waltham: Elsevier, 2013.

FANG, Wei. Using Google Analytics for improving library website content and design: A case study. Journal of Web Librarianship: New York, 2007 p. 1-17. Disponível em:

\footnotetext{
7 Adaptado e traduzido de forma livre a partir das colocações de Fang (2007), segue trecho original com parte dessa afirmação: Google Analytics can report facts about the monitored website but is unable to make suggestions on how to improve it.
}

$16^{\circ}$ Ergodesign - Congresso Internacional de Ergonomia e Usabilidade de Interfaces Humano Tecnológica: Produto, Informações Ambientes Construídos e Transporte

$16^{\circ}$ USIHC - Congresso Internacional de Ergonomia e Usabilidade de Interfaces Humano Computador

CINAHPA | 2017 - Congresso Internacional de Ambientes Hipermídia para Aprendizagem.

http://digitalcommons.unl.edu/

HASSENZAHL, Marc. User Experience (UX): Towards an experiential perspective on product quality. 2008. Não paginado. Disponível em: $<$ http://www.marc-hassenzahl.de/pdfs/hassenzahlihm08.pdf>. Acesso em: 19 nov 2016.

User Experience and Experience

Design. Disponível em: <http://www.interactiondesign.org/encyclopedia/

user_experience_and_experience_design.html >. Acesso em: 19 nov. 2016.

HASSENZAHL, Marc; TRACTINSKY, Noam. User experience - a research agenda. Behaviour and Information Technology, London, v. 25, n. 2, p. 91-97, 2006. Disponível em:

$<$ http://www.informaworld.com/openurl? genre $=$ article $\&$ doi $=10.1080 / 01449290500330331$

$\&$ magic $=$ crossref $>$. Acesso em: 19 nov. 2016.

ORDUÑA, Octavio Isaac Rojas. Blogs: la conversación en Internet que está revolucionando medios, empresas, políticos y ciudadanos. Madrid: Esic Editorial, 2006. 316 p.

ROGERS, Yvonne; SHARP, Helen; PREECE, Jennifer. Design de Interação: Além da Interação Humano-Computador. 3. ed. Porto Alegre:

Bookman, 2013.

TEIXEIRA, J. M.; BENEDET G. V.;PINTO A. L.. Proposta de framework para validação de personas: um estudo de caso com base em análise de clusters. Educação Gráfica, Bauru, v. 20, n. 3, p.375-394, dez. 2016. Disponível em:

<http://www.educacaografica.inf.br/>. Acesso em: 18 fev. 2017.

TERRA, Carolina Frazon. Blogs corporativos: modismo ou tendências? Rio de Janeiro: SENAC Rio, 2012.

WAISBERG, Daniel; KAUSHIK, Avinash. Web Analytics 2.0: empowering customer centricity. The original Search Engine Marketing Journal, v. 2, n. 1, p. 5-11, 2009
Realização:

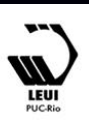

